\title{
Operações psicopolíticas dos evangélicos durante as eleições presidenciais de 2018
}

\author{
Psychopolitic operations from evangelical groups \\ during presidential elections in 2018
}

\author{
Lília Dias Marianno \\ Programa de Pós-Graduação em História das Ciências e das Técnicas e Epistemologia \\ (HCTE), Universidade Federal do Rio de Janeiro (UFRJ). \\ lilia.marianno@ufrj.br; lilia.marianno@gmail.com \\ http://orcid.org/0000-0003-1436-2611
}

\section{Evandro Vieira Ouriques}

Programa de Pós-Graduação em História das Ciências e das Técnicas e Epistemologia (HCTE), Universidade Federal do Rio de Janeiro (UFRJ).

evandro.vieira.ouriques@gmail.com

http://orcid.org/0000-0003-1000-8447

Resumo. O presente trabalho é uma resposta à análise feita por Evandro Vieira Ouriques em sua conferência intitulada "Desobediencia psicopolítica frente al perspectivismo de la gobernancia y sus políticas públicas: el caso de Brasil” apresentada em Setembro de 2018 na Universidad de La Plata na Argentina. Este ensaio estende a discussão iniciada pelo autor na perspectiva das operações psicopolíticas dos diferentes grupos denominados evangélicos em ação nas eleições presidenciais de 2018.

Palavras-chave: Teoria psicopolítica. Eleições presidenciais. Religião. Evangélicos. Trânsito religioso.

Abstract. This paper is a response to Evandro Vieira Ouriques' analisis in his conference titled "Desobediência psicopolítica frente al perspectivismo de la gobernancia y sus políticas públicas: el caso de Brasil” presented in September of 2018 at the Universidad de La Plata in Argentina. This essay extends the discus- 
sion started by the author about psychopolitic operations overview of different evangelical groups in action during Brazilian presidential elections in 2018.

Keywords: Psychopolitic theory. Presidential elections. Religion. Evangelical groups. Religious transit.

Recebido: 08/10/2018 Aceito: 28/10/2018 Publicado: 07/11/2018

\section{Introdução}

$\mathrm{O}$ artigo de Ouriques, intitulado "Desobediencia psicopolítica frente al perspectivismo de la gobernancia y sus políticas públicas: el caso de Brasil" (OURIQUES, 2018) teve como ponto de partida o choque e a desorientação resultantes de operações psicopolíticas que destituíram poderes políticos na América Latina e no Caribe na segunda década do século XXI, operações estas que coincidem com a volta do fascismo como um fenômeno de grandeza mundial. Tais movimentos culturais e políticos nos obrigam a fazer uma revisão das teorias sociais que asseguravam a governança dos partidos de esquerda na América Latina e Caribe.

Este artigo responde às duas perguntas lançadas por Boaventura de Souza Santos naquele mesmo ano de 2018 quando referiu-se à Nicarágua, a saber: 1) Por que as alianças com as diferentes forças de esquerda parecem sempre mais difíceis que as alianças entre a esquerda hegemônica e as forças de direita? 2) Por quanto tempo a memória de conquistas revolucionárias impede a capacidade de denunciar as perversidades que lhes seguem, até o ponto de que a denúncia chegue, quase sempre, tarde demais?

Ouriques explica que é preciso transitar em rede do perspectivismo ontológico, com sua base dualista (que prevalece orientando as teorias sociais e as filosofias hegemônicas do Ocidente), para a condição comunicacional do ser humano (condição não-metafísica e não-individualista) na qual somos instituídos propriamente como humanos, pois é esta condição, a de instituir-se na escuta da voz do outro (da voz da mãe, da voz do pai, da voz da função mãe, da função paterna e da função fraterna, no sentido da antropobiologia filosófica e da antropologia da linguagem) a única maneira de possibilitar a conversa emancipatória, dada a fragilidade biológica do ser humano que o obriga a criar psiquismos e redes de psiquismos, as instituições à semelhança da segurança e da proteção sem as quais não se institui como humano.

Ou seja, como ele explica, quando aqueles que dialogam referem-se uns aos outros narrando a si mesmos e dando razões para seus pensamentos, palavras e atos (logon didonai) em uma maneira que privilegia o convencimento (a palavra que se destina ao outro enquanto outro) em detrimento da persuasão (a palavra que se destina a conformar o outro a determinados objetivos), acentuando assim as boas razões em detrimento 
da produção de resultados, portanto em constante parrhesia (franqueza, confiança, ousadia) -quando a palavra verdadeira e corajosa assume o risco de dizer a verdade e de aceitar a possibilidade de receber a palavra do outro como verdadeira ao ponto dela revelar uma imagem de nós mesmos e do que se experimenta que não reconheçamos e que a partir desta conversa se reconheça como verdadeiro.

É assim que o estado de exceção prevalece quando a condição comunicacional é ignorada e, por exemplo, as políticas públicas centradas nas políticas de identidade esquecem de tratar dos traumas nela causados pelo dualismo (id.), traumas que se manifestam no fascismo de baixa intensidade presente nas relações, e assim na fragmentação intra e inter identidades e na recusa à autocrítica, quando o necessário é, por isto, sincronizar intervenções nos territórios com intervenções nos territórios mentais (OURIQUES, 2009) envolvidos.

De acordo com Ouriques, é apenas a superação do dualismo que permite escapar da tensão dilaceradora entre a ontologia da "unidade, identidade e transcendência [,] (...) dos regimes de servidão organizados a partir de Deus, do Soberano, ou seja, do Grande Outro" (OURIQUES, 2018, p. 150) -que gerou tantos males, e continua a gerar como estamos analisando neste artigo, dado o autoritarismo que ela necessariamente gera- e a ontologia da pluralidade e da diferença que não consegue gerar, respondendo a Boaventura, as alianças entre as forças de esquerda, fragmentadas pelas disputas de narrativas, certas da inexistência da verdade apesar de clamarem por ela sob as denominações de justiça social, equidade econômica, respeito à diferença, etc., o que implica, para tornálas fato e valor, uma ontologia não-dualista, como a que orienta a teoria psicopolítica (OURIQUES, 2017a).

Assim como Ouriques respondeu aos referidos questionamentos de Boaventura de Souza Santos, este artigo se coloca a serviço da conversa emancipatória de que trata a teoria psicopolítica, reconhecendo e evidenciando as operações psicopolíticas que possibilitaram o apoio majoritário dos evangélicos ao candidato Jair Bolsonaro.

Nosso roteiro estabeleceu a distinção conceitual e histórica entre os diferentes grupos evangélicos e protestantes que coexistem no Brasil, evidenciando as transformações demográficas nestes grupos demonstradas no Censo do IBGE de 2010 e o modo como isso se refletiu no engajamento eleitoral do segmento evangélico.

\section{Distinção entre diferentes grupos evangélicos}

Quando falamos de "evangélicos" no Brasil não estamos falando de uma grandeza homogênea, de mesma matriz histórica ou com um direcionamento ideológico comum. Estudos de Ciências da Religião (nos campos de Fenomenologia, História Comparada, Sociologia, Antropologia, Psicologia e Geografia das Religiões) mostram os evangélicos multifacetados e com posicionamentos políticos antagônicos entre si. Por isso é importante elucidar sobre qual segmento evangélico estamos pretendendo falar. Mas isto 
não será possível sem uma revisão sobre a geografia sociopolítica onde estes grupos estão inseridos. O modo como estes grupos surgem no Brasil já foi delineado com detalhamento em trabalho anterior, apresentado no X Scientiarum Historia (MARIANNO, 2017). Para fins de referência, relembramos apenas que existem minimamente cinco grandes grupamentos denominados "evangélicos" no Brasil, e se incluímos os grupos católicos, temos seis grandes segmentos de matriz cristã no país.

a) Os grupamentos católicos tradicionais chegaram o Brasil a partir do descobrimento, em maiores levas por causa da contrarreforma (que por definição é uma clara operação psicopolítica) e enviou os jesuítas para catequizar os índios.

b) Os protestantes reformados (calvinistas franceses e reformados holandeses) chegaram nos séculos XVI e XVII em pouca quantidade, marcadamente em levas das invasões francesa e holandesa, mas não se consolidaram significativamente no Brasil neste primeiro momento.

c) Os protestantes de imigração chegaram da Europa a partir da primeira metade do século XIX, a saber: Anglicanos (1816), Luteranos (1824) e Congregacionais (1855) e não tinham uma atuação essencialmente proselitista.

d) Os protestantes de missão chegaram na segunda metade do século XIX, oriundos dos Estados Unidos tendo o proselitismo como senso de missão. Este grupo trouxe consigo fortíssima ideologia capitalista e antissocialista, dogmaticamente consolidada no modelo religioso conservador estadunidense. Uma primeira parte destes grupos chegou ao Brasil escapando da derrota na Guerra Civil norteamericana, e pelo Brasil ainda preservar o trabalho escravo. Somente anos depois é que a segunda leva de protestantes de missão vieram com intenções missionárias e consolidaram grupos como os Batistas, Presbiterianos e Metodistas ${ }^{1}$.

e) Na virada para o século XX chegaram os grupos pentecostais, oriundos também dos Estados Unidos, com espírito missionário proselitista e deram origem a igrejas como as Assembleias de Deus, a Congregação Cristã do Brasil, a Igreja de Cristo, Igreja do Evangelho Quadrangular², Igreja do Nazareno e Igreja de Nova Vida.

f) A partir da segunda metade do século $X X$ surgem os grupos neopentecostais. Embora o neopentecostalismo seja um movimento de natureza avivalista que representa uma tendência mundial, ao se estabelecerem no Brasil estes grupos tiveram contornos muito próprios e seus fundadores ainda são vivos e muito presentes nas emissoras de TV como: Igreja da Graça (Missionário R.R. Soares),

\footnotetext{
${ }^{1}$ No protestantismo de missão incorpora-se uma noção salvacionista da humanidade que entende-secomo “destino manifesto". Nos Estados Unidos os protestantes de missão são fortemente engajados com o Partido Republicano e com o conservadorismo que apoia intervenções militares em outros países ou a eleição do presidente Donald Trump.

${ }^{2}$ Segmento evangélico original da ministra Damares Alves.
} 
Igreja Universal do Reino de Deus (Edir Macedo), Igreja Apostólica Mundial (Valdemiro Santiago), Igreja Renascer (Estevam e Sônia Hernandes) entre os mais famosos. O neopentecostalismo é considerado como movimento sectário dos grupos pentecostais e no seu bojo há divergências ideológicas significativamente contrastantes, conforme estudos acadêmicos inumeráveis de cientistas da religião.

\section{Operações psicopolíticas evangélicas nas eleições}

Para fins de análise das operações psicopolíticas, interessa-nos saber que os grupos listados em (b) possuem como mentalidade a separação entre Igreja e Estado. Esta ideologia deveria representar os grupos listados também em (c) e (d), mas o atual trânsito religioso intenso entre os diversos segmentos carrega consigo trânsito de ideologias, por isso, muitos protestantes passaram a comportar-se como neopentecostais. A mentalidade psicopolítica (pois envolvem ao mesmo tempo as atitudes pessoais e as atitudes políticas) destes grupos vem se confundindo com a mentalidade psicopolítica dos grupos listados em (e) e (f), que desprezam a laicidade do Estado e impõem (sobre as tomadas de decisões nas questões civis e pátrias) uma teologia interpretada a partir do viés dogmático conservador, moralista e fundamentalista, onde se mostram os prejuízos que o dualismo causa aos psiquismos e às redes de psiquismos, as instituições, perpetuando inúmeros regimes de servidão ${ }^{3}$.

Um dado estatístico, nada banal, é o crescimento destes grupos evangélicos retratado no Censo do IBGE de 2010. Diante da diferenciação entre os grupos (b), (c), (d), (e) e (f) apresentadas no Censo, destacamos o mapa da Diversidade Religiosa ${ }^{4}$, que classifica 148 diferentes religiões no Brasil. Uma única categoria foi criada para agrupar as religiões Católica, Espírita, Umbanda, Candomblé e Sem Religião. Mas dentro do segmento evangélico existem todas as subclassificações mencionadas anteriormente, acrescida da categoria Evangélicas Não Determinadas.

O Censo do IBGE de 2010 evidencia que, entre os grupos denominados cristãos, caiu o percentual de Católicos Romanos (73 para 65\%) e manteve-se inalterado o percentual de Evangélicos de Missão (4,1\%). Aumentaram os Evangélicos Pentecostais e Neopentecostais $(10,4$ para 13,4\%) e Evangélicos Não Determinados (1 para 4,9\%).

Isto significa que no Estado Laico brasileiro 87,3 \% da população se declara religiosa de tradição cristã e crescem significativamente os grupos neopentecostais e indetermina-

\footnotetext{
${ }^{3}$ Os estudos sobre o impacto do trânsito religioso e destas interferências muito interessam aos pesquisadores de ciência política, antropologia e sociologia. Neste sentido o impacto do trânsito religioso em processos decisórios na nação vem sendo amplamente pesquisado e nos principais PPGs em Ciências da Religião do país como os da Universidade Federal de Juiz de Fora e Universidade Metodista de São Paulo (TEIXEIRA \& MENEZES, 2006).

4 Cf. Atlas do Censo Demográfico 2010 (2013). IBGE: Rio de Janeiro. Disponível em: <http://censo2010.ibge.gov.br/apps/atlas/> Acessado em: 14/07/2017.
} 
dos. Os grupos Pentecostais e Neopentecostais abominam a noção de Estado Laico, o que é um risco gravíssimo para o Estado de Direito, como se vê nos resultados das eleições. Por estes grupos o preâmbulo da Constituição poderia perfeitamente ter um texto teocrático à semelhança de versículos bíblicos. De tais contextos surgem segmentos fundamentalistas radicais como o grupo conhecido como Igreja Geração Jesus Cristo, cujo slogan é: "Bíblia sim, constituição não", fundado por Tupirani da Hora Lores ${ }^{5}$, preso por discriminação religiosa, incitação à violência, racismo e homofobia. Estas divergências de mentalidade se refletem claramente na quantidade de evangélicos concorrendo à presidência e de não insignificantes $1,26 \%$ dos votos válidos para personagens desconhecidos na política e com discursos semelhantes às pregações em igrejas pentecostais como aconteceu com o Cabo Daciolo ${ }^{6}$.

Não podemos esquecer que o recrudescimento do fascismo é um fenômeno mundial (OURIQUES, 2018), que ele diagnostica como sendo provocado pela manutenção do dualismo como base do pensamento, uma vez que apenas o dualismo é capaz de gerar um outro como externalidade absoluta na qual se projeta no outro o mal absoluto, portanto uma identidade para o extermínio, ou o bem absoluto, então uma identidade para a salvação. Desta forma o recrudescimento do fascismo atinge os grupos com ideologias salvacionistas de modo mais radical, e neste sentido os grupos (c), (d), (e), (f) estão grandemente engajados.

Em tese, os grupos Protestantes de Missão deveriam manter uma neutralidade política ou uma isenção de manifestação pública de engajamento político uma vez que defendem a separação entre Igreja e Estado e possuem o regime congregacional e a governança é orientada por decisões democráticas tomadas em assembleias. Pastores protestantes são funcionários da comunidade e podem ser inclusive demitidos se a assembleia assim o determinar.

Os grupos Pentecostais e Neopentecostais sempre funcionaram numa base nãodemocrática, na qual os pastores são considerados representantes de Deus na Terra e a autocracia ganha níveis teocráticos. O sistema impede que sejam questionados ou depostos. Muitas igrejas destes segmentos adotam a Teologia da Prosperidade. Trata-se de uma teologia de enriquecimento rápido, fenômeno estudado intensamente pelos cientistas da religião. Esta teologia acabou ganhando muitos adeptos entre as lideranças protestantes. A teologia da prosperidade prega um sistema de retribuição, no qual, quanto

\footnotetext{
${ }^{5}$ Denúncia: quem são o pastor, a igreja e os fieis evangélicos radicais com discurso de ódio no RJ. in Ativismo Protestante: liberdade de expressão e senso crítico. Publicado em 20/08/20178. Disponível em: $<$ https://ativismoprotestante.wordpress.com/2017/08/20/denuncia-quem-sao-o-pastor-a-igreja-e-os-fieisevangelicos-radicais-com-discurso-de-odio-no-rj/> Acesso em: 16/10/18. Tupirani da Hora Lores possui um canal no Youtube onde difunde sua ideologia e encontra-se disponível em: <https://www.youtube.com/channel/UC1WCTW_N8NfzIj_qP4yn0gQ> Acesso em: 16/10/18.

${ }^{6}$ Eleições 2018: Decisão fica para segundo turno entre Bolsonaro e Haddad. Publicado em: 7/10/2018. Disponível em: <https://www.bbc.com/portuguese/brasil-45766626> Acesso em: 16/10/18.
} 
mais dinheiro o fiel dá, mais ele será "abençoado" por Deus. Para sustento desta mentalidade usa-se o texto bíblico de maneira conveniente e descontextualizada.

Lo mismo les ocurre a los capitalistas: los éxitos de las empresas sólo confortan a sus patrones en la certeza de su salvación moral y social a condición de que puedan abstener-se de disfrutar inmediatamente de los beneficios obtenidos y de que, para reforzar su amplitud y eficacia, los reinviertan de nuevo en el desarrollo de las mismas relaciones de producción. Este doble movimiento de búsqueda y de experimentación sobremultiplicada de los deseos, al igual que de intransigente áscesis, transforma la acción de producción en fin absoluto e implica una capitalización económica del poder político en el que se hace soberana abstracción del fin de esta experimentación: del bien supremo de todos, de su felicidad social e individual. Sólo se hace actuar al prójimo con vistas a asegurarse la propia perfección y la propia salvación moral: con vistas a asegurarse la armonía que se comprueba entre el mérito obtenido en la acción y la felicidad de capitalización que de ello deriva. Se disfruta exclusivamente de la posibilidad de subordinar el bienestar del prójimo a la conciencia de la propia perfección moral, en la que uno ha puesto de antemano toda su felicidad. Uno busca maximizar su propia certeza de salvarse: se trata de una perversión inherente a la intención moral que habita en la experimentación total (POULAIN; 2027, p. 39).

Os grupos neopentecostais estão mais representados nos espaços socioeconômicos e geográficos de vulnerabilidade social. Por isso foi um enorme contrassenso que tantos neopentecostais tenham apoiado um candidato que se posicionava abertamente contrário aos programas sociais que beneficiassem estas populações. Durante os mandatos anteriores estes grupos atribuíram seu crescimento econômico e mobilidade social como respostas de Deus às suas ofertas e dízimos captados com o forte apelo da Teologia da Prosperidade. Quando a crise econômica mundial atingiu ao Brasil tardiamente, a partir de 2014, estes grupos interpretaram a perda do emprego e a queda na ascensão econômica como "obra do diabo" e culparam os governos populares das gestões passadas pelo colapso na economia, desemprego e empobrecimento. Esta externalidade absoluta do mal na direção de um outro absoluto lhes garante que a autocrítica é desnecessária, pois o mal reside sempre no outro e não em si próprio (entendido o mal aqui como o conjunto de estados metais incompatíveis com os que caracterizam a condição comunicacional do ser humano). Desta maneira o processo psicopolítico de "demonização absoluta do PT" teve grande adesão dos líderes religiosos dos segmentos neopentecostais adeptos da teologia da prosperidade, desta "prosperidade" em detrimento do outro.

O engajamento de tais líderes com um candidato à presidência de perfil moralista, conservador e de extrema-direita que prometia a "retomada do crescimento", a recusa hostil das conquistas das liberdades de gênero, sexo e corpo e "Deus acima de tudo", inclusive acima do Brasil, atendeu às expectativas de sustentação dos discursos dualistas dos líde- 
res destes grupos. Isto explica o grande apoio dos grupos neopentecostais e dos protestantes em trânsito para a eleição do atual presidente da república.

\section{Regimes psicopolíticos de servidão}

Como dito anteriormente, os grupos pentecostais e neopentecostais são fundados numa base teocrática afinada com sistemas de coação psicopolítica pelo forte viés ideológico impregnado na prática religiosa, o que colabora para a instalação dos regimes de servidão irredutíveis, sem qualquer prospecção de retomada da condição comunicacional do ser humano. O resultado das eleições representa um produto desta mentalidade, desta qualidade de território mental.

O acolhimento dos neopentecostais às propostas neoliberais está em consonância com a ideologia da prosperidade pregada nestes segmentos, exemplificando o que Ouriques (2018) disse:

El golpe de 2016, como se sabe, se realizó y fue sostenido hasta ahora em el apoyo voluntario de grande parte de la poblacion brasileña, mobilizada contra si misma por uma estratégia psicopolitica (...) que trabajo y trabaja em la frontera entre la psicopatologia y la politica (...) estrategia implantada por vía mediática, parlamentaria y judiciaria, y por la dificultad de la outra grande parte de la poblacion em reaccionar de manera efectiva a esta inesperada (para muchos) vuelta del fascismo, pues "la paradoja última del pensamiento lógico es que el es autodestructivo cuando se cultiva de forma diligente" (OURIQUES, 2018, p.3-4).

Entre as operações psicopolíticas mais nefastas no segmento evangélico está a do "voto cajado" 7 a versão protestante do que seria o "voto cabresto" do coronelismo. ONGs evangélicas de orientação protestante estiveram engajadas na denúncia destes regimes de servidão. Inúmeras lideranças participaram de petições públicas de rechaço a este controle das lideranças religiosas sobre o voto dos fieis ${ }^{8}$. Os pastores protestantes que aderiram insanamente à conduta dos neopentecostais ${ }^{9}$ demonizavam o PT alegando não quererem que o Brasil se transformasse numa "segunda Venezuela".

O crescimento dos evangélicos não foi ignorada e nem banalizada pela estratégia de marketing do candidato vencedor. Em 2016 quando a campanha estava sendo estrategicamente articulada o candidato foi registrado pela imprensa sendo batizado por

\footnotetext{
7 Voto cajado: o escândalo da política evangélica. Publicado em 10/09/2018. <http://redefale.blogspot.com/2014/09/voto-de-cajado-o-escandalo-da-politica.html> Acessado em: 05/10/2018.

8 Carta pastoral à nação brasileira: <https://peticaopublica.com.br/pview.aspx?pi=cartapastoral2018> Acessado em 05/10/2018.

${ }^{9}$ Pastores declaram apoio a Jair Bolsonaro em meio a protestos no Brasil. Publicado em: 01/10/2018. Disponível em: <https://guiame.com.br/gospel/mundo-cristao/pastores-declaram-apoio-jair-bolsonaroem-meio-protestos-no-brasil.html> Acessado em 05/10/2018.
} 
um pastor pentecostal no Rio Jordão em Israel ${ }^{10}$. Esta foi mais uma operação psicopolítica muito inteligente pois o batismo no meio evangélico é sinônimo de adesão e pertença ao segmento e que escapou às teorias sociais e filosofias hegemônicas que ainda as impede de perceber que o que chamam dualisticamente de "imaterial", "mental", "subjetivo" é o que determina o que chama pelas mesmas razões de "material", "concreto", "objetivo". Foi assim que para estruturar uma sólida plataforma de apoio junto às lideranças dos segmentos moralistas e conservadores ${ }^{11}$ que passaram a vê-lo como um "irmão de fé" (sendo usado o jargão "irmão vota em irmão").

Parte do que fez uma considerável porção do segmento evangélico realizar esta opção teve relação com as noções de segurança e proteção, as quais nos referimos inicialmente como o estado mental no qual o ser humano por se instituir como propriamente humano e que por isto ele assume como figura de felicidade. Tanto uma segurança social e civil quanto uma segurança dogmática moralista que se vê ameaçada diariamente pelas perspectivas de inclusão reivindicadas por grupos ativistas de Direitos Humanos que são tratados como grupos que contrariam os princípios de obediência ao livro sagrado. Isto está explicado no texto de Ouriques, quando fala d centralidade da segurança e da proteção em todos os regimes de servidão, que em uma das mãos as ameaça e na outra as oferece em troca da servidão voluntária, existindo por isso (e por exemplo) na América Latina mais segurança privada do que professores, a força policial dobrou nos últimos anos, quintuplicou em relação a 1890 e o valor de investimentos em segurança privada supera o montante de ajuda global para a superação da pobreza mundial.

As operações psicopolíticas que externalizaram o mal em termos absolutos em relação ao PT, preservaram a fragilidade do território mental dos sujeitos movidos pelo vazamento em estado bruto de seus inconscientes -entendido o inconsciente aqui no sentido reichiano, ou seja, de depósito dos traumas causados pela mentalidade hegemônica no cerne biológico amoroso do ser humano, categoria de certa maneira aproximável da categoria aqui referenciada de condição comunicacional do ser humano- e por isto incapazes do exercício da autocrítica e assim da conversa emancipadora, fizeram com que o então candidato à presidência, Jair Messias Bolsonaro, fosse interpretado por muitos evangélicos como o candidato mais interessado na segurança (inclusive por ser representante do segmento militar, mesmo que dele tenha sido afastado ainda no início de sua carreira), embora esteja amplamente comprovado que conceder liberdade para civis andarem armados não confere qualquer segurança efetiva aos sujeitos e suas sociedades.

Como o golpe militar-empresarial de 1964 foi basicamente nutrido por interesses geopolíticos dos Estados Unidos psicopoliticamente disfarçados sob a alegação da necessi-

\footnotetext{
${ }^{10}$ Para muitos evangélicos o batismo perdeu o seu significado histórico de arrependimento de pecados e, desde muito cedo na história do cristianismo passou a representar pertença e fidelização de pertencimento ao segmento batizador. Ao ser batizado por um pastor pentecostal muitos pentecostais consideraram o candidato como um membro de seu segmento, devido à sacralidade do rito do batismo.

11 Jair Bolsonaro é batizado no rio Jordão. Publicado em 12/05/2016. Disponível em: < https://noticias.gospelprime.com.br/jair-bolsonaro-batizado-rio-jordao/> Acessado em 05/10/2018.
} 
dade de não se ter uma segunda Cuba ${ }^{12}$ no Brasil, em 2018 o discurso, o mesmo de certa forma, alegava evitar aqui uma "segunda Venezuela". O golpe de 1964 foi apoiado por grande parte das confissões protestantes de missão no Brasil já que o segmento neopentecostal ainda estava nascendo. Por terem herdado estas noções imperialistas e republicanas dos Estados Unidos, os evangélicos dos anos 60 praticamente em massa apoiaram o golpe e os generais foram muitas vezes recebidos com honraria nas tribunas das igrejas.

\section{Conclusão}

A tendência de evangélicos apoiarem regimes totalitários e candidatos que os representam é histórica. Embora os regimes comunistas também tenham ficado conhecidos na história como regimes totalitários, os evangélicos só atacam o comunismo pelo histórico de repressão religiosa original destes regimes. A associação demonizada e sem discernimento da diferença entre comunismo e socialismo ainda se faz presente em grande parte destes grupos. O imaginário é o de estarmos ainda na Guerra Fria.

O nome cristão advém da terminologia "pequenos cristos". O exemplo do Cristo deveria ser orientador dos cristãos, pois ele agiu naturalmente restabelecendo o diálogo emancipatório, abominando extremismos e intolerâncias. No entanto os evangélicos tem aderido a sistemas imperialistas, à semelhaça do imperialismo romano, que transforma o ser humano em coisa, em produto, que o desumaniza. Esta adesão diverge totalmente da mensagem de amor, paz e tolerância deixada pelo Cristo.

A mística cristã só perde com tudo isso. O Deus do monoteísmo cristão ficou transformado na imagem humana quando foi disputado pelo poder. Faltou aos evangélicos a possibilidade do intervalo, do "entre" (OURIQUES, 2018, p. 157), deste espaço intermediário entre os extremos onde se é possível dialogar e se chegar ao comum: ao lugar não-dualista em que "semelhança" e "diferença" se encontram (OURIQUES, 2005). Pois apenas na presença da semelhança que é possível experimentar-se diferença, e vice-versa. Apenas uma ontologia não-dualista permite a conversa emancipatória.

Muitos evangélicos que se posicionaram na contramão do candidato vitorioso foram ridicularizados, humilhados, desqualificados e afrontados nas redes sociais. Este tipo de procedimento é antidemocrático e acima de tudo, anticristão, provando que ser evangélico no Brasil a partir das eleições de 2018 deixou de significar "ser cristão".

\section{Financiamento}

O presente trabalho foi realizado com apoio da Coordenação de Aperfeiçoamento de Pessoal de Nível Superior - Brasil (CAPES) - Código de Financiamento 001.

\footnotetext{
12 Ver apoio dos evangélicos ao golpe de 64 no documentário: "O dia que durou 21 anos" do jornalista Flavio Tavares dirigido por Camilo Galli Tavares, 2012. Publicado em 22/10/2016. Disponível em: $<$ https://www.youtube.com/watch?v=4ajnWz4d1P4\&t=228s $>$ Acessado em: 05/10/2018.
} 


\section{Referências}

MARIANNO, Lília Dias. Diversidade de gênero versus intolerância religiosa. O conflito sob as lentes da lógica e da antropologia hiperdialética. Publicado em: Julho de 2017. Disponível em: https://ufri.academia.edu/liliamarianno. Acesso em: 16/10/2018.

POULAIN, Jacques. Sobre la capacidad de juzgar. Volumen II, Colección Teoría Psicopolítica. Universidad de La Frontera-Chile, Universidade Federal do Rio de Janeiro-Brasil, Universidad Nacional de La Plata, Argentina, Universidade do Porto, Portugal e Universidade de Groningen-Holanda, 2017.

OURIQUES, Evandro Vieira. Comunicação, educação e cidadania: quando diversidade e vinculação social são apenas um. in Saúde e Cidadania, Revista do Centro de Ciências da Saúde, Universidade Federal do Rio de Janeiro, Nº 1, Vol. 1. UFRJ: Brasil.

Território mental: o nó górdio da democracia. in Revista Democracia Viva, IBASE. No 49, maio de 2009. IBASE: Brasil.

Desobediência psicopolítica frente al perspectivismo de la gobernancia y sus políticas públicas: el caso de Brasil. in SAINTOUT, Florencia; MARROQUÍN, AMPARO; DEL VALLE, Carlos. Comunicación, política y ciudadanía. CLACSO: Argentina. Disponível em: https://ufrj.academia.edu/EvandroVieiraOuriques Acesso em $16 / 10 / 2018$.

Teoria Psicopolítica: a emancipação dos aparelhos psicopolíticos da

Cultura. Volumen I, Colección Teoría Psicopolítica. Universidad de La Frontera-Chile, Universidade Federal do Rio de Janeiro-Brasil, Universidad Nacional de La Plata, Argentina, Universidade do Porto, Portugal e Universidade de Groningen-Holanda, 2017.

A teoria psicopolítica como renovação da teoria social e da filosofia. In: ROJAS C.V.; ECHETO, V. S. (Editores). Crisis, comunicación y crítica política. Quito/Equador: CIESPAL. pp. 310-341.

TEIXEIRA, Faustino; MENEZES, Renata (2006). As religiões no Brasil: continuidades e rupturas. Petrópolis: Vozes. 